\title{
The Need for Environmental and Safety Consciousness for Sustainable Industrial Development in Nigeria: A Review
}

\author{
Anthony Okoye (PhD) \\ Department of Environmental Management, \\ NnamdiAzikiwe University, Awka, Nigeria
}

doi: 10.19044/esj.2017.v13n26p345 URL:http://dx.doi.org/10.19044/esj.2017.v13n26p345

\begin{abstract}
Safety and environmental protection should be one of the strategic priorities for industries, multinational corporations, Non- Governmental organizations and indeed all Nigerians in their respective sectors. The extent of environmental and safety consciousness in Nigeria industries was reviewed in this paper. In Nigeria, industrialization and mechanization are increasing while occupational health problems are becoming prominent. On the same note, industrial development also brings, in its wake; problems of environmental pollution that often need abatement. Occupational Safety has been reported to be poor and still at infancy in Nigeria where most industries do not treat their wastes at all before discharging their effluents into the environment. The way forward for enhancing the safety and environmental consciousness were suggested. Awareness creation and enforcement are the two major steps to take to achieve a holistic safety and environmental compliance of industries.
\end{abstract}

Keywords: Safety, Environmental, Industries, Awareness, Enforcement

\section{INTRODUCTION}

I strongly feel that it is the wish of everybody to live in a world that is equitable and without poverty; a world that respects human right and is environmentally, socially and economically sustainable; and a world where all the global environmental challenges has been successfully addressed. This could however be achieved, but unfortunately according to Brundtland et al., (2012), humanity's behaviour remains utterly inappropriate for dealing with the potentially lethal fallout from a combination of increasingly rapid technological devolution matched with very slow ethical-social evolution.

Safety and environmental protection should be one of the strategic priorities for industries, multinational corporations, Non- Governmental 
organizations and indeed all Nigerians in their respective sectors. According to Abdullahi and Ugbede (2013), keeping the environment healthy and safe wherever we work or do our business is a core value of every citizenry and it is the responsibility of the Nigerian government to oversee and monitor the safety of the environment

In Nigeria, industrialization and mechanization are increasing while occupational health problems are becoming prominent. Health problems resulting from such hazards may appear to occur less frequently than other major disabling diseases, due to lack of knowledge and pattern of illness of such hazardous diseases (Kalejaiye, 2013). While hazards varied according to occupation, some of the most prevalent problems amongst workers include; lack of Personal Protective Equipment (PPE), exposure to hazardous chemicals and dusts and long hours of work. The most prevalent health impairments are musculo-skeletal disorders and low back pain; allergic reactions and other respiratory disorders; physical strain, fatigue and stress. For instance, it is common to see some artisans lifting heavy loads manually, working without protective gadgets, putting dirty oils on the road, eating without washing hands, playing in shops, using sensitive equipment without seeking permission and testing live cables with bare hands among others. In Nigeria however, Adeogun and Okafor (2013) reported that the perspectives of most industries and organisations show that the stage of occupational health and safety is still at infancy in the country due to employer/employee attitudinal behaviour, lack of safety culture and non-implementation of OHS policies.

The development and widespread use of new packaging substances such as plastics have improved the standards of living for millions, but they have also introduced new threats to the environment, as typified by the histories of dichlorodiphenyltrichloroethane (DDT) and polychlorinated biphenyls (PCBs). Thus, industrial development also brings in its wake problems of environmental pollution that often need abatement. From the foregoing, it could be seen that there is really an urgent need for environmental and safety consciousness amongst all and sundry including the government, the employers and employees. This is what this paper seeks to highlight.

\section{THE EXTENT OF SAFETY CONSCIOUSNESS IN NIGERIA INDUSTRIES}

Industrial disasters, especially those resulting in multiple fatalities, make global headlines. But the reality is that throughout the world, many thousands of people die from their work activities every day, and numerous fatalities are unreported or ignored (ILO, 2014). Out of about 75 percent of hospitalized and ambulatory primary care patients that reported hazardous 
exposures, 17 percent suspect that their illness is linked to their jobs (Schwartz et al, 1991; Newman, 1995).

Inadequate safety and health standards and environmental hazards are particularly evident in most Nigerian Industries. For instance, although there are no reliable accident data in Nigeria (Idoro 2008; Okolie\&Okoye 2012), a study by Ezenwa (2001) over a 10-year period (1987-1996) of fatal injuries reported to the Federal Ministry of Labour and Productivity (Inspectorate Division) shows that out of 3183 injuries reported, 71 were fatal. In fact between 1990 and 1994, the overall fatality rate as recorded by the Ezenwa (2001) is $22 \%$ of the above reported cases (Umeokafor et al; 2014). It was reported by Diugwu et al. (2012) that the failed occupational safety and health $(\mathrm{OSH})$ management system in Nigeria is due to the non-functional $\mathrm{OSH}$ regulations and provisions. However, it is argued that enforcement and compliance with OSH regulations are not the stand-alone steps for improving OSH, as improving organisational culture can also improve OSH.

The Nigerian Federal Ministry of Labour and Productivity (Inspectorate Division) enforces OSH regulations while the National Council for Occupational Safety and Health will enforce the Labour, Safety, Health and Welfare Bill of 2012 in Nigeria when passed into law. So far, the efficacy and accountability of the Federal Ministry of Labour and Productivity in the enforcement of OSH regulations in Nigeria are evidently questionable and poor (Umeokafor et al; 2014a). The research carried out by Umeokafor et al (2014b) on the Compliance with Occupational Safety and Health Regulations in Nigeria's Public Regulatory entity revealed that 10 out of 48 staff of the Federal Ministry of Labour and productivity Inspectorate Division in Nigeria that were observed and interviewed failed to comply with some OSH regulations that they should enforce thus establishing the upstream decay of enforcement and compliance with OSH regulations in Nigeria. This could perhaps be because OSH enforcement is not the principal practice in Nigeria (Okolie\&Okoye 2012) or as a result of lack of safety culture in the entire system.

\section{THE EXTENT OF ENVIRONMENTAL CONSCIOUSNESS IN INDUSTRIES}

Although industrialization is inevitable, various devastating ecological and human disasters which have continuously occurred over the last four decades, implicate industries as major contributors to environmental degradation and pollution problems of various magnitude (Abdel-Shafy and Abdel-Basir, 1991; Asia and Ademoroti, 2001; Amoo et al., 2004). Industrial activities debase the environment around us, affecting the land we live on, the water we use and the air we breathe. Many industrial activities are responsible for discharging waste into the environment, and these waste 
contain many poisonous substances that will contaminate the soil (Akanmu and Adenike; 2010).

Ironically, industrial corporations do not consider adequately the functionality of their waste treatment plant (for the few that have it) so as to accommodate basic treatments such as sedimentation, sand filtration, oil and grease traps and precipitators for gaseous emissions (Aina 1992, Adebayo 2007). Actually, most of these industries in Nigeria do not treat their wastes at all before discharging their effluents into the environment. These wastes and emission contain toxic and hazardous substances, most of which are detrimental to human health (Rajaram and Ashutost, 2008; Ogunfowokan et.al. 2005 and Jimena et. al 2008). These include heavy metals such as lead, cadmium and mercury, and toxic organic chemicals such as pesticides, PCBs, dioxins, polyaromatic hydrocarbons (PAHs), petrochemical and phenolic compound (Rao et al., 1998; Njoku et. al., 2009; and Gbadebo et al., 2010). Several studies carried out on effluents discharged from industries show that most heavy metals exceed their allowable limits (Adeyeye, 2002, Ademoroti, 2001; Amoo et al., 2004). Akanmu and Adenike (2010) reported that industrial pollution is clearly one of the biggest contributions to their polluted land, especially in the western part of Nigeria.

In Nigeria, it is known that Small and Medium Enterprise (SMEs) are responsible for large share of business environmental impact. They are much less preoccupied about their image as good environmental citizens rather they focus all their energy in increasing their production as well as income. Then there comes a crucial question: " Is it that they are ignorance of the regulations, laws and the impact of their activities on the environment, or that they out rightly want to dam the consequences and carry on their activities without recourse to the environmental laws"? A key factor affecting the compliance behaviours of SMEs is their limited competence and capacity to adopt approaches of environmentally sound industrial development. Their compliance is also hindered by the perception that environmental protection is costly and has little benefit to their businesses. Moreover, it has equally been observed that they have scarce knowledge of the environmental aspects of their activities and worse still they are ignorant of the environmental regulations and laws due mainly to little or no awareness programmes by the government.

In Nigeria, enforcing environmental standards and regulations have become a difficult task. Faced with several environmental challenges the need to effectively enforce environmental laws cannot be overemphasized. Unfortunately, according to Benebo (2008) ( the former Director General of National Environmental Standard and Regulation Enforcement Agency (NESREA), the rates of non-compliance with environmental laws, regulations and standards have continued to be high. More so, there is 
inadequate awareness amongst policy makers which relegates environmental matters to the background, with decimal appropriation; inadequate awareness amongst judiciary and difficulty in getting police cooperation in terms of arrest and custodial facilities among others. From the foregoing, it could be inferred that the level of environmental consciousness amongst the industrial players are still very low and hence there is dire need to urgently arrest this situation which threatens the survival of our future generation.

\section{THE WAY FORWARD}

Safety and environmental protection as earlier discussed are strategic priorities for the Nigerian Government, industries, multinational corporations, Non- Governmental organizations and indeed all Nigerians in their respective domains. Having assessed the level of environmental and safety consciousness in industries, the way forward is discussed below accordingly.

\section{SAFETY CONSCIOUSNESS}

The need for prevention is both obvious and urgent. The great majority of workplace accidents and diseases are preventable, but good intentions have not always been implemented or sustained. While some may be tempted to cut back on occupational safety and health (OSH), especially during an economic downturn, it remains true that "good safety is good business". Prevention is part of a survival strategy; those who sustain their efforts to prevent occupational accidents and diseases will find their efforts rewarded. Incidentally, the nature of occupational diseases is changing rapidly, as new technologies and global social changes aggravate existing health risks and create new ones and so the need for prevention is both obvious and urgent. Hence, prevention is part of a survival strategy.

A way of maintaining a safe organization is by integrating a safety culture into the organization's values. Safety culture is necessary for the adopted occupational health and safety management model described above to flourish in an organization (Adeogun and Okafor , 2013). One in which safety has a special place in the concerns of those who work for the organization. Once safety is in place in an organization's culture, the organization can be regarded as having a safety culture. But it is after a certain stage of development of such culture that the organization can be said to take safety sufficiently serious to be identified with a safety culture (Adeogun and Okafor , 2013).

Thus innovative and simple means of preventing occupational accidents and diseases and promoting workers health and safety is by giving industrial employees training on work safety and other related studies to help them to know their responsibility on work safety. The introduction of simple 
and low-cost improvements in working practices, programmed control of occupational and work-related hazards through basic training and awareness programme on health and safety and the creation of safety and health committees within the industries would drastically reduce the number of casualties recorded amongst this labour segment (Tomei, 1997)

The training and awareness programme would benefit not only the country but employers and their employee with their families as highlighted below:

1. It would make the employers to commence prompt and routine reporting of accidents to the Ministry/Council as required by the law.

2. It would drastically reduce the number of casualties recorded amongst the workers

3. It would reduce man-hour loss

4. It would increase significantly the economic status of the employers and their employees and the country as well

5. It would make the workers to be psychologically ready to perform better

6. The awareness would serve as a final warning for the implementation of the appointment of a safety officer in every company.

The problem of OSH enforcement in Nigeria should be tackled head on by the government. In fact, the responsibility rests on the government to improve the state of the OSH in Nigeria, along with active participation of the trade unions, professional bodies, educational institutions and employer to play significant roles (Umeokafor et al; 2014)

\section{ENVIRONMENTAL CONSCIOUSNESS}

The need for a healthy environment is a fundamental prerequisite for sustainable development. Enforcing environmental standards and regulations is one of the surest ways governments can use to checkmate the negative impacts of industrial activities on the environment and on the lives of inhabitants of host communities. Without an effective environmental enforcement culture, one that is capable of ensuring compliance by big and small enterprise, it is expected that the quality of the environment will be drastically reduced. Worse still, most industries do not do the environmental audit required of them every three years which is meant to assess the impact created so far after the previous audit. The National Environmental Standard and Regulation Enforcement Agency whose duty is it to enforce the law is yet to accomplish that. Worse still; instead of collaborating with other relevant State Ministries and Parastatal for collective implementation, the state Ministries of Environment fight with NESREA over the authority to enforce. This has worsened the situation because most State Ministries hire quack consultants in most cases who do cut and paste environmental audits 
just to generate revenue for themselves while undermining the protection of environment.

The way forward for ensuring better compliance and environmental consciousness is for NESREA to fully discharge their duty as the environmental watchdog of the country. Moreover, the following suggestions according to Ibrahim and Imam (2015) would help;

$\checkmark$ Mounting a robust and sustained awareness campaign on environmental laws;

$\checkmark$ Provision of Infrastructure and logistics for monitoring and enforcement;

$\checkmark$ Greater cooperation among stakeholders at all levels nationally and internationally;

$\checkmark$ Stepping up system-wide communication and information sharing for speedy response and dispensation of environmental matters;

$\checkmark$ Capacity building and Manpower development for Scientist and enforcement officers;

$\checkmark$ Routine appreciation workshop for Judges/other law enforcement Agencies on extant environmental Laws.

$\checkmark$ Strong synergy among stakeholders

$\checkmark$ Domestication of the already signed MEAs

\section{CONCLUSION}

Safety and environmental protection should be one of the strategic priorities of the Nigerian government towards a healthy national development of the nation. Nigeria should consider that health, safety and respect for the environment are essentials to the well- being and standard of living of its citizens. Awareness creation and enforcement are the two major steps to take to achieve a holistic safety and environmental compliance of industries. The Federal Ministry of Labour and Productivity (Inspectorate Division) and the National Council for Occupational Safety and Health should collaborate with the employers of labour in the industries to achieve adequate safety consciousness while NESREA should strengthen relationship with law enforcement agents ranging from IG, DSS, Military and other paramilitary groups for their assistance in monitoring, arrest and sealing of defaulters premises in order to foster adequate environmental consciousness. These actions would help a lot in ensuring sustainable growth of industries in Nigeria.

\section{References:}

1. Abdel-Shafy, H.I. and Abdel-Basir, S.E.( 1991) Chemical treatment of industrial wastewater. Environmental Management and Health; 2(3): $19-23.2$. 
2. Akanmu,A.S and Adenike, F.K. (2010) Pollution of Ibadan Soil by Industrial Effluents, New York Science Journal, vol;3(10) :37-41

3. Adebayo OT (2007). Chemical analysis of some industrial effluent that discharge into Lagos Lagoon, Nigeria.

4. Adeogun, B.K and Okafor, C.C. (2013) "Occupational health, safety and environment (HSE) trend in Nigeria," Journal of Environmental Science, Management and Engineering Research. 2(1), pp.24-29, http://www.ijesme r.com.

5. Adeyeye EI (2002). Assessment of the physico-chemical status of a textile industry. Pak. J. Sci. 45 (1) 10-16.

6. Aina EOA (1992). Halting industrial pollution in Nigeria which way FEPA. In: Towards industrial pollution abatement in Nigeria. Aina EOA and Adedipe NO (Eds), pp: 13-19.

7. Amoo, I.A., Ajayi, O.O., Ipinmoroti, K.O. and Amuda, O.S.( 2004) Performance of some coagulants in the treatment of effluent from soap/detergent industry. Proceeding 27th of International Conference of Chemical Society of Nigeria, Benin: $415-420$.

8. Asia, I.O. and Ademoroti, C.M.A.( 2001) Performance of some coagulants/flocculants in the physico- chemical treatment of aluminium extrusion sludge. Proceeding of Chemical Society of Nigeria.

9. Benebo, N.S., (2008). "The role of NESREA in environment management, protection and enforcement". Being a presentation delivered at MAN 2008 on Environmental Management, Ikeja, November, 17

10. Brundtland, H.B., Ehrlich, P., Goldemberg,J., Hansen,J., Lovins,H., Likens, G., Manabe,S., May,B., Mooney,H., Robert,K., Salim, E., Sato,G., Solomon,S., Stern,N., Swaminathan,M, Watson, R., Barefoot College, Conservation International, IIED and IUCN (2012) Environment and development Challenges: The Imperative to act. The ASAHI GLASS FOUDATION, Tokyo, Japan, URL:http://www.af-info.or.jp

11. Diugwu I.A; Baba D.L; Egila A.E; (2012) Effective Regulation and Level of Awareness: An Exposé of the Nigeria's Construction Industry. . Open Journal of Safety Science and Technology, 2012. Vol. 2, pp 140-146

12. Ezenwa, A. O. (2001) A Study of Fatal Injuries in Nigerian Factories. Society of Occupational Medicine,. Vol. 51 (8), pp 485-489. Federal Republic of Nigeria. Labour, Safety Health and Welfare Bill.

13. Ibrahim , M. and Imam, K. (2015) Overview of Environmental Laws, Regulations, and Multilateral Environmental Agreements In Nigeria. 
A paper presented at the UNEP Global Training Programme on Environmental Law and Policy, 5th - 13th October, Nairobi, Kenya

14. Idoro, G. I. (2011) Comparing Occupational Health and Safety (OHS) Management efforts and Performance of Nigerian Construction Contractors. Journal for Construction in Developing Countries, Vol. 16 (2), pp 151-173.

15. Idubor E.E and Oisamoje, M.D.( 2013) An Exploration of Health and Safety Management Issues in Nigeria's Effort to Industrialize. European Scientific Journal; 9(12).

16. ILO (2014) A world without fatal work accidents is possible. Available at: http://www.ilo.org/global/about-the-ilo/mediacentre/press- releases/WCMS_301233/lang--en/index.htm. Accessed September, 2015.

17. (ILO, 2014) Safety and health at work : a vision for sustainable prevention: XX World Congress on Safety and Health at Work 2014: Global Forum for Prevention, 24 - 27 August 2014, Frankfurt, Germany / International Labour Office. - Geneva:

18. International Labour Office G.(2012) Estimating the Economic cost of Occupational Injuries and Illnesses in Developing countries: Essential Information of Decision- makers.: Available at http://www.ilo.org/wcmsp5/groups/public. Assessed September, 2015.

19. Jimena, M.G., Roxana, O., Catiana, Z., Margarita, H., Susana, M. and Ines-Isla M.(2008) Industrial effluents and surface waters genotoxicity and mutagenicity evaluation of a river of Tucuman, Argentina. J. of hazardous Material,; 155(3): 403-406.

20. Kalejaiye, P.O.(2013) Occupational Health and Safety: Issues, Challenges and Compensation in Nigeria. Peak Journal of Public health and Management,. Vol. 1 (2), pp 16-23.

21. Musa Sabo Abdullahi andAkpokerieRoselineUgbede (2013) Environmental Safety and Sustainability: A Panacea for Healthy National Development in Nigeria, Academic Journal of $\begin{array}{lllll}\text { Interdisciplinary } \quad \text { Studies, } & \text { Vol } & \text { No } & 13\end{array}$ Doi:10.5901/ajis.2013.v2n13p77

22. Okolie, K. C., and Okoye, P.U. (2012) Assessment of National Cultural Dimensions and Construction Health and safety climate in Nigeria. Science Journal of Environmental Engineering Research,. Vol. 2012, 6 pgs

23. Ogunfowokan, A.O., Okoh, E.K., Adenuga, A.A. and Asubiojo, O.I.( 2005) An assessment of the impact of point source pollution from a university sewage treatment oxidation pond on a receiving stream - a preliminary study. Journal of Applied Sciences; 5(1):36 - 43. 
Rajaram, T. and Ashutost, D.(2008) Water pollution by industrial effluents in India: discharge scenario and case for participatory ecosystem specific local regulation. Envr. J. 2; 40(1): 56-69.

24. Schwartz DA, Wakefield DS, Fieselmann JF, Berger-Wesley M, Zeitler R. (1991) The occupational history in the primary care setting. Am. J. Med.;90:315-9.

25. Tomei I. M (1997) A different perspective: Industrial Relations and the Informal Sector in ILO, World Labour Report, (in press)

26. Umeokafor N, Isaac D, Jones K, Umeadi B. (2014) Enforcement of occupational safety and health regulations in Nigeria: An exploration. European Scientific Journal ; 3:93-104.

27. Umeokafor, N. Umeadi, B., Jones, K and Igwegbe, O. (2014) Compliance with Occupational Safety and Health Regulations in Nigeria's Public Regulatory entity: A Call for Attention, International of Scientific and Research Publications, vol.4(5). 